\title{
Performance evaluation and optimization of steam generating systems
}

\section{C.S. BALADHIYA AND J.S. DOSHI}

Received : 03.01.2017; Accepted : 26.03.2017

See end of the Paper for authors' affiliation

Correspondence to :

\section{C.S. BALADHIYA}

College of Agriculture, Anand Agricultural University, JABUGAM (GUJARAT) INDIA Email : csbaladhiya@gmail. com
-ABSTRACT : Steam is widely used as heating medium for thermal processing of dairy and food products. Steam is produced in boiler using various types of fuels such as coal, fuel oil, natural gas, biogas etc. In the wake of the tremendous rise in fuel price and decline in the fuel supply in the recent year, there is a need of economizing the energy utilization. The efficient generation of steam depends mainly on regular monitoring of operating parameters such as combustion process, excess air control, water treatment, regular maintenance, monitoring of flue gas temperature etc. The knowledge of various parameters affecting the performance is a basic requirement for the optimization of the steam generating system. The automatic controls used in modern boilers have improve the efficiency of boiler by optimizing operating parameters required for efficient combustion process and to achieve safety in operation of fuels. Operation of boiler under optimum conditions not only helps in reducing the cost of steam generation but also helps in reducing the air pollution.

- KEY WORDS : Boiler, Steam, Energy management, Fuel

- HOW TO CITE THIS PAPER : Baladhiya, C.S. and Doshi, J.S. (2017). Performance evaluation and optimization of steam generating systems. Internat. J. Agric. Engg., 10(1) : 221-226, DOI: 10.15740/HAS/IJAE/10.1/221-226. 